\title{
TEMPERATURA E INHIBIDORES DE GIBERELINAS EN EL PROCESO DE FLORACIÓN DEL MANGO 'ATAULFO'
}

\section{TEMPERATURE AND GIBBERELIN INHIBITORS IN THE FLOWERING PROCESS OF MANGO CV. 'ATAULFO'}

\author{
Ma. Hilda Pérez-Barraza ${ }^{*}$, Edilberto Avitia-García², Raquel Cano-Medrano ${ }^{3}$, \\ Ma. Alejandra Gutiérrez-Espinosa ${ }^{3}$, Tomás Osuna-Enciso ${ }^{4}$ y Adriana Isabel Pérez-Luna ${ }^{1}$
}

\begin{abstract}
'Instituto Nacional de Investigaciones Forestales, Agrícolas y Pecuarias, Nayarit, México. ${ }^{2}$ Universidad Autónoma de Chapingo, Estado de México, México. ${ }^{3}$ Colegio de Postgraduados, Postgrado en Recursos Genéticos y Productividad-Fruticultura, Campus Montecillo, Estado de México, México. ${ }^{4}$ Centro de Investigación en Alimentación y Desarrollo, Culiacán, Sinaloa, México.
\end{abstract}

\section{RESUMEN}

La iniciación y diferenciación floral está controlada por factores exógenos, endógenos y hormonales. El objetivo fue determinar el efecto del paclobutrazol (PBZ), prohexadiona de calcio ( $\mathrm{P}-\mathrm{Ca}$ ) y temperatura en la diferenciación floral del mango (Mangifera indica L.). El estudio se realizó durante los ciclos 20132014 y 2014-2015 en un huerto comercial de mango 'Ataulfo' de 8 años de edad. Los tratamientos fueron: 1) Tres aplicaciones de $500 \mathrm{mg} \cdot \mathrm{L}^{-1} \mathrm{de} \mathrm{P}-\mathrm{Ca}$ a los 30, 45 y 60 días después de la poda (ddp); 2) Una aplicación de $2500 \mathrm{mg} \cdot \mathrm{L}$ ${ }^{1}$ de PBZ a 30 ddp y 3) Testigo asperjado con agua y surfactante. En ambos ciclos, la iniciación y diferenciación floral fue 45 y 30 días más temprana en las yemas donde se aplicó PBZ y P-Ca, respectivamente, con relación al testigo. El porcentaje de yemas diferenciadas fue mayor con los inhibidores de giberelinas, $63 \%$ con PBZ y $15 \%$ en testigo durante el ciclo 2013-2014 y $73 \%$ - $28 \%$ durante el ciclo 2014-2015; resultados similares se obtuvieron en el porcentaje de floración. La iniciación floral en yemas se estimuló con temperaturas nocturnas alrededor de $15^{\circ} \mathrm{C}$ y los inhibidores de la síntesis de GAs aceleraron el proceso de diferenciación.

Palabras clave: Mangifera indica L., diferenciación floral, paclobutrazol, prohexadiona de calcio, reguladores de crecimiento.

\section{SUMMARY}

Initiation and floral differentiation is controlled by exogenous, endogenous and hormonal factors. The aim was to determine the effect of paclobutrazol, calcium prohexadione and temperature on floral differentiation of mango (Mangifera indica L.). The study was conducted during 2013-2014 y 20142015 in a mango cv 'Ataulfo' commercial orchard eight years old. Treatments were: 1) Three applications of $500 \mathrm{mg} \mathrm{L}^{-1}$ of P-Ca at 30,45 and 60 days after pruning (dap); 2) One application of $2500 \mathrm{mg} \cdot \mathrm{L}^{-1}$ of PBZ at 30 (dap) and 3) Control, where water and surfactant were applied. In both cycles, the floral initiation and differentiation was 45 and 30 days earlier in the buds where PBZ and P-Ca were applied, respectively, in regard to the control. The percentage of differentiated buds was higher with the gibberellin inhibitors, $63 \%$ with PBZ and $15 \%$ in control during the cycle $2013-2014$ and $73 \%-28 \%$ during the cycle 2014-2015; similar results were obtained in flowering percentage. Bud floral initiation was stimulated by nocturnal temperature near to $15^{\circ} \mathrm{C}$ and the inhibitors of GAs synthesis accelerated the differentiation process.

Index words: Mangifera indica L., floral differentiation, paclobutrazol, calcium prohexadione, growth regulators.

\section{INTRODUCCIÓN}

En Nayarit, el comportamiento fenológico anual de 'Ataulfo' ha variado durante los últimos 10 años. Otoños cálidos con alta humedad en el suelo se han asociado con floraciones irregulares o en algunos casos nula floración, ocasionando rendimientos y calidad de fruto bajos. El proceso de floración en frutales está regulado por factores exógenos y endógenos (Bangerth, 2009). En el aspecto hormonal, aparentemente las giberelinas (GAs) funcionan estimulando crecimiento vegetativo en lugar de reproductivo. Hay evidencias de que la aplicación de reguladores como paclobutrazol (PBZ) y prohexadiona de calcio (P-Ca), que reducen el crecimiento vegetativo, favorecen floración al inhibir la biosíntesis de GAs (Rademacher, 2015).

Para modificar floración en mango se ha dependido fuertemente del PBZ (Pérez-Barraza et al., 2011; MartínezFuentes et al., 2013), un inhibidor de las enzimas de biosíntesis de GAs en la etapa II (Rademacher, 2015). P-Ca, otro inhibidor de GAs, es usado en frutales templados, (Atay y Koyuncu, 2017), pero su uso en mango es muy escaso (Do Carmo-Mouco et al., 2011). Aunque se conoce el efecto sobre floración, la información del efecto de estos reguladores en los procesos de iniciación y diferenciación floral del mango es escasa y nula en el caso de mango 'Ataulfo'.

En mango, la inducción floral es estimulada por temperaturas bajas en condiciones subtropicales $\left(15 / 10{ }^{\circ} \mathrm{C}\right.$ de día/noche), pero en condiciones tropicales se ha reportado que la edad del brote es el factor dominante por la ausencia de bajas temperaturas (Sandip et al., 2015). La iniciación floral (IF) en mango se caracteriza por un ligero alargamiento del eje principal y formación de protuberancias meristemáticas en las axilas de los primordios foliares, mientras que en la diferenciación floral (DF) hay alargamiento de los ejes terciarios de la inflorescencia y 
la formación y desarrollo de meristemos reproductivos (Pérez et al., 2009; Palanichamy et al., 2012). La duración y época en que ocurre la DF varía entre especies, cultivares, ambiente y manejo del cultivo. En mango ocurre normalmente a finales de otoño y principios de invierno, con una duración entre cuatro y seis semanas (Pérez et al., 2009; Palanichamy et al., 2012).

Por otro lado, se documenta que el PBZ es capaz de inducir floración sin presencia de temperaturas frescas en los trópicos. En mango 'Keitt' y 'Tommy Atkins' con sólo dos semanas en temperaturas inductivas $\left(10 / 15^{\circ} \mathrm{C}\right)$, el PBZ redujo el número de días requeridos para floración, lo que indicó que el regulador complementó la necesidad de bajas temperaturas para la inducción floral (Yeshitela et al., 2004). En mango 'Khiew Sawoey', a los 104 y 112 días después de la aplicación de PBZ el 90 y $100 \%$ de los brotes tratados florecieron, mientras que ninguna de las yemas control desarrolló flores (Tongumpai et al., 1996). Considerando lo anterior, el objetivo del presente estudio fue conocer el efecto de PBZ, P-Ca y temperatura en el proceso de iniciación y diferenciación floral del mango 'Ataulfo'. Este conocimiento apoyará el uso eficiente de estos reguladores para lograr floraciones regulares y anticipadas en el mango 'Ataulfo', lo que significará un mayor rendimiento y mejor precio en la venta del producto.

\section{MATERIALES Y MÉTODOS}

El estudio se realizó en el municipio de Santiago Ixcuintla, Nayarit, durante los ciclos de floración del mango de 20132014 (clima cálido $>30 / \geq 20^{\circ} \mathrm{C}$ día/noche) y de 2014-2015 (clima fresco $>20 / \leq 15^{\circ} \mathrm{C}$ día/noche) (Cuadro 2). Se seleccionó un huerto comercial de mango 'Ataulfo'/criollo regional de 8 años de edad establecido con alta densidad (1330 árboles/ ha). El huerto se manejó con un sistema de riego por goteo, poda lateral (despunte de aproximadamente 30 cm, sólo en lado oriente y poniente) y fertilización con $2 \mathrm{~kg}$ de Triple 17 por árbol al inicio de la temporada de lluvias (junio) y 1 kg de fertilizante orgánico (gallinaza) por árbol aplicado en septiembre. En dicho huerto se seleccionaron 36 árboles de vigor similar (diámetro del área transversal del tronco alrededor de $15 \mathrm{~cm}$ ).

Los tratamientos evaluados fueron tres: 1) Aplicación de $500 \mathrm{mg} \mathrm{L}^{-1}$ de P-Ca a los 30, 45 y 60 días después de la poda (ddp); 2) $2500 \mathrm{mg} \mathrm{L}^{-1}$ de PBZ a 30 ddp y 3) Testigo, en donde se aplicó agua más surfactante. Las dosis utilizadas son resultados de trabajos previos realizados con estos inhibidores (Pérez et al., 2016). La solución de P-Ca (Apogeeß) se preparó con agua corriente y se usó $1 \mathrm{ml} \mathrm{L}^{-1}$ de surfactante Inex®, el cual se aplicó al follaje a punto de goteo mediante bomba aspersora. El PBZ (Austar®) se aplicó bañando el tallo principal a una altura de $30 \mathrm{~cm}$ de la base del suelo. En todos los casos se trataron 12 árboles por tratamiento.

\section{Muestreo de yemas}

En 2013-2014 seis árboles se destinaron para el muestreo de yemas y los seis restantes fueron conservados para evaluar el efecto en floración. En cada árbol se marcaron aproximadamente 80 brotes del flujo de verano (emergidos después de la poda de cosecha) alrededor y en la parte media del árbol. De cada árbol y brotes seleccionados se tomaron al azar cuatro yemas apicales cada 15 días de septiembre 30 a noviembre 30 y cada 8 días de diciembre hasta inicio de floración (13 y 26 de febrero y 6 de abril en PBZ, P-Ca y testigo, respectivamente). Se muestrearon entre 60 y 72 brotes por árbol; el resto de brotes fue desechado. A las yemas se les eliminó la mayoría de las escamas, se fijaron en FAA (50 \% etanol al $100 \%+5 \%$ ácido acético glacial $+10 \%$ formaldehído $+35 \%$ agua destilada), se incluyeron en parafina, se cortaron en un micrótomo rotatorio (8 micrometros) y se observaron al microscopio (Pérez-Luna et al., 2015). En 2014-2015, en seis árboles (similar al ciclo anterior) se marcaron 24 brotes por árbol del flujo de verano y se registró el estadio de iniciación y diferenciación en un periodo similar al ciclo anterior, considerando la escala generada en 2013-2014.

\section{Variables evaluadas}

1) Morfología de yemas. En el primer ciclo, para caracterizar interna y externamente el proceso de iniciación y diferenciación floral, se estableció una escala con cuatro estadios morfológicos de la yema, con base en los resultados presentados para 'Tommy Atkins' (Pérez et al., 2009): Estadio 1 (E1), yema vegetativa, Estadio 2 (E2), iniciación floral, Estadio 3 (E3), yema determinada y Estadio 4 (E4), yema diferenciada. La apariencia externa se utilizó para evaluar el proceso durante 2014-2015. 2) Inicio de diferenciación (ID). Se consideró la fecha en la cual un $5 \%$ de las yemas muestreadas se encontraban en E2 y se contabilizaron los días a partir del primer muestreo (30 de septiembre) hasta la fecha en que ocurrió E2. 3) Duración del proceso de diferenciación. En las mismas yemas se contabilizaron los días a partir del primer muestreo (30 de septiembre) hasta la fecha en que ocurrió E4, posteriormente se restaron los días en que ocurrió E2. 4) Porcentaje de yemas diferenciadas. Se evaluó considerando el número de yemas que alcanzaron E4 entre el total de yemas muestreadas. 5) Porcentaje de floración. Se evaluó en seis árboles restantes que no fueron usados para muestreo de yemas, ya que estos últimos se despuntaban en cada fecha de muestreo. Semanalmente se registró el porcentaje de inflorescencias que cubrían la copa del árbol a partir del inicio (5\% de floración) hasta plena floración (80 \%). 6) Plena floración. Se 
contabilizaron los días a partir del primer muestreo (30 de septiembre) hasta la fecha en que el $80 \%$ de inflorescencia cubrían la copa del árbol.

Se registró además la temperatura y precipitación colocando en el huerto un sensor higrotermógrafo (HOBO Pro Serie ${ }^{\circledR}, \mathrm{RH}$ Temp; Onset Computer Corporation, USA), donde se registraron las temperaturas máxima y mínima cada media hora, de septiembre a febrero del siguiente año. Los datos de precipitación fueron tomados de la red de estaciones agroclimáticas de INIFAP.

El diseño experimental fue completamente al azar en los dos ciclos productivos. Se evaluaron tres tratamientos con 6 repeticiones y un árbol como parcela útil para las variables porcentaje de floración y días a plena floración. En las variables inicio de la diferenciación, duración del proceso y porcentaje de yemas diferenciadas, las repeticiones fueron 24 yemas apicales por tratamiento. Se efectuó análisis de varianza de los resultados y se usó la prueba de Tukey $(P \leq 0.05)$ para comparación de medias. Se utilizó el programa SAS versión 9.2. (SAS, 2013).

\section{RESULTADOS Y DISCUSIÓN}

\section{Morfología de yemas}

Anatómicamente, el meristemo vegetativo se presentó en forma de cúpula, con primordios foliares y sin presencia de meristemos en las axilas de los mismos (Figura 1A). Externamente, la yema presentó una forma puntiaguda con escamas completamente cerradas (Figura 1B). En la iniciación floral (E2), las yemas muestran un ligero alargamiento del meristemo apical y presencia de meristemos de ejes secundarios en las axilas de las brácteas (Figura 1C). Morfológicamente, la yema estaba ensanchada en su base, con ligera separación de escamas en el ápice (Figura 1D). En E3 hubo un alargamiento vigoroso del eje principal de la inflorescencia (raquis), con crecimiento de ejes secundarios en ápice y protuberancias de ejes terciarios (Figura 1E). Exteriormente, la yema presentó una forma redonda con escamas completamente separadas (Figura $1 F$ ). Las yemas diferenciadas, E4, se caracterizaron por el alargamiento de los ejes terciarios de la inflorescencia, formación de meristemos reproductores $(\mathrm{mr})$ en las axilas de los hipsófilos (hi) y el desarrollo de primordios florales, sépalos, pétalos y estambres (Figura 1G). Esto es, que la inflorescencia emergió entre las brácteas y no hubo presencia de escamas (Figura 1H). Palanichamy et al. (2012) definieron cuatro estadios importantes del proceso de diferenciación, E1 incisión floral, E2 yema determinada, E3 desarrollo de ejes secundarios y aparición de terciarios y E4 yema diferenciada, que coinciden en parte con los caracterizados en este estudio a partir de E2. Aunque, Pérez et al. (2009) definieron 12 estadios de desarrollo de la yema en 'Tommy Atkins' de E1 yema vegetativa a E12 antesis. En el presente estudio sólo se caracterizaron cuatro estadios, donde el último (E4) coincidió con yemas diferenciadas, similar a lo reportado por ambos autores; en yemas E4 ocho días después se observó la aparición de inflorescencias.

\section{Inicio de la diferenciación y duración del proceso}

En el primer ciclo, la iniciación y diferenciación floral ocurrió primero en yemas con PBZ, con una duración desde E2 hasta E4 de 30 días (Cuadro 1). Con P-Ca la iniciación (E2) se presentó 15 días después que en PBZ y las yemas estuvieron diferenciadas (E4) 28 días después de la iniciación (Cuadro 1). Las yemas del testigo iniciaron el E2 1.5 y un mes después que PBZ y P-Ca, respectivamente; la duración del proceso fue mayor que en PBZ y P-Ca con 39 días (Cuadro 1; $P \leq 0.05$ ). En el segundo ciclo, en los brotes de los árboles tratados con PBZ se determinó que la diferenciación ocurrió primero que en los brotes de los árboles donde se aplicó P-Ca y los árboles testigos. Así, cuando se aplicó la P-Ca, E2 ocurrió 15 días después que cuando se aplicó PBZ. En el testigo, en el que la fase E2 ocurrió 46 y 31 días después que en PBZ y P-Ca (Cuadro 1), respectivamente, y las yemas alcanzaron el E4 36 días después de la iniciación, el proceso de diferenciación fue mayor (Cuadro $1 ; P<0.05)$.

Los resultados muestran que el proceso de E2 hasta E4 fue más corto (entre 25 y 30 días) cuando se aplicó P-Ca y PBZ. En mango, el proceso ocurre normalmente a finales de otoño y principios de invierno, con una duración entre cuatro y seis semanas (Pérez et al., 2009; Palanichamy et al., 2012). Aunque la duración y época en que ocurre varía entre especies, cultivares, ambiente y manejo del cultivo (Palanichamy et al., 2012), en este estudio los resultados indican que la aplicación de PBZ y P-Ca adelantaron la iniciación del proceso, con mayor eficiencia en PBZ. Por otra parte, la aplicación de P-Ca, aunque E2 inicia ligeramente más tarde que PBZ, el proceso completo fue de menor duración. Al respecto, se sabe que las GAs inhiben la diferenciación floral promoviendo crecimiento vegetativo, por lo que inhibidores de su síntesis como PBZ y P-Ca pueden favorecer el proceso (Yeshitela et al., 2004; Abdel-Rahim et al., 2011; Upreti et al., 2013).

El PBZ bloquea el citocromo P450 dependiente de monooxigenasas, que cataliza la oxidación de ent-kaureno vía ácido ent-kaurenóico. Por otro lado, las últimas etapas de la biosíntesis de GA son catalizadas por dioxigenasas, que requieren ácido 2-oxoglutárico como co-sustrato. Debido a su relación estructural con el ácido 2-oxoglutárico P-Ca inhibe esta reacción, inhibiendo la formación de GAs activas y formando precursores inactivos (Rademacher, 2015). 

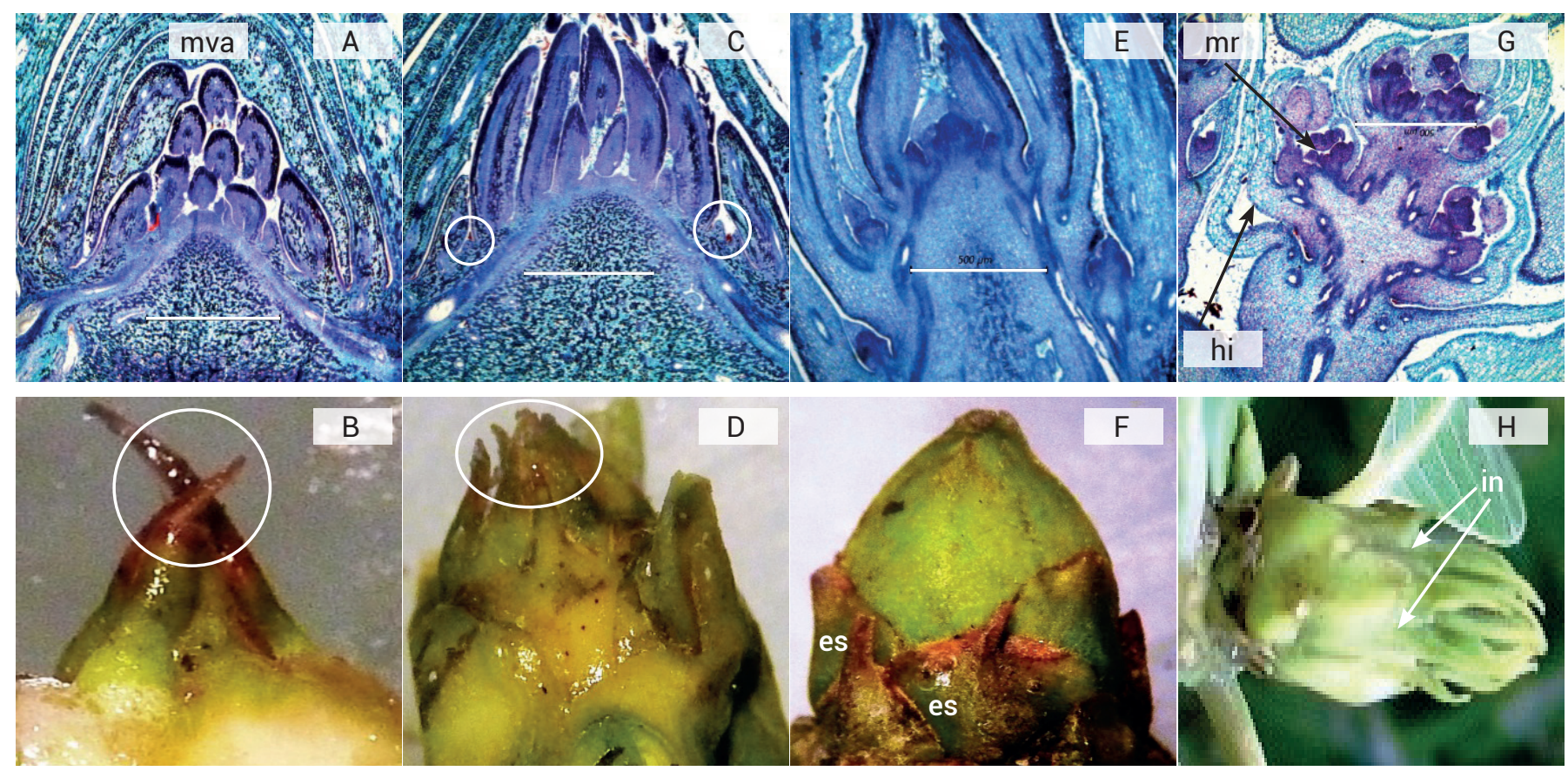

Figura 1. Microfotografías y fotografías de yemas de mango 'Ataulfo' durante la diferenciación floral. Estadio 1. Corte anatómico del meristemo vegetativo apical (mva) (A) y apariencia externa (B). Estadio 2. Corte anatómico de iniciación floral (C) y su apariencia externa (D). Estadio 3. Yema determinada (E) y su apariencia externa (F). Estadio 4. Yema diferenciada (G) y su aspecto externo previo a la emergencia de la inflorescencia (in) (H).

Cuadro 1. Número de días al inicio de la diferenciación floral (E2), yema diferenciada (E4), período entre E2 y E4 y días a Plena Floración en dos ciclos de floración de mango 'Ataulfo'.

\begin{tabular}{|c|c|c|c|c|c|c|c|c|}
\hline \multirow[b]{2}{*}{ Tratamiento $\mathrm{mg} \cdot \mathrm{L}^{-1}$} & \multicolumn{3}{|c|}{$2013-2014$} & \multicolumn{3}{|c|}{$2014-2015$} & \multicolumn{2}{|c|}{$\mathrm{DPF}^{+}$(días) } \\
\hline & E2 & E4 & $\mathrm{DP}^{\dagger}$ (días) & E2 & E4 & DP (días) & 2014 & 2015 \\
\hline PBZ $2500^{++}$ & $97 c^{9}$ & $129 \mathrm{c}$ & $30 \mathrm{~b}$ & $73 \mathrm{c}$ & $104 \mathrm{c}$ & $31 \mathrm{~b}$ & $161 \mathrm{c}$ & $136 b$ \\
\hline P-Ca 1500 & $112 b$ & $140 \mathrm{~b}$ & $28 b$ & $88 b$ & $113 b$ & $25 c$ & $176 b$ & $146 b$ \\
\hline Testigo & $142 \mathrm{a}$ & $181 \mathrm{a}$ & $39 a$ & $119 a$ & $155 a$ & $36 a$ & $206 a$ & $182 \mathrm{a}$ \\
\hline CV & 5.7 & 2.7 & 8.2 & 5.6 & 3.4 & 9.3 & 5.6 & 4.9 \\
\hline DMSH & 5.3 & 3.2 & 2.1 & 4.3 & 3.5 & 1.9 & 13.9 & 10.3 \\
\hline
\end{tabular}

${ }^{\dagger} \mathrm{DP}$ : duración del proceso expresado en días de E2 a E4; DPF: días a plena floración. ${ }^{+t}$ : Una aplicación de PBZ a 30 ddp; tres aplicaciones de P-Ca a 30+45+60 ddp. : Medias con letras iguales no son estadísticamente diferentes (Tukey, 0.05). CV: Coeficiente de variación. DMSH: Diferencia mínima significativa honesta.

La iniciación floral, en los dos ciclos evaluados, ocurrió en los meses donde las temperaturas nocturnas fueron alrededor de $15^{\circ} \mathrm{C}$, enero en el primer ciclo y noviembrediciembre en el segundo (Cuadro 2). Estos resultados difieren de lo mencionado por varios autores, indicando que la iniciación es estimulada por temperaturas bajas en condiciones subtropicales, mientras que en condiciones tropicales la edad fisiológica del brote (aproximadamente seis meses de edad) es más importante para que inicie el proceso, porque las temperaturas bajas son escasas o nulas (Sandip et al., 2015). En nuestro estudio, tanto el PBZ como la P-Ca promovieron floración solo en presencia de temperaturas frescas, lo que indica que estas temperaturas, junto con los reguladores, estimularon el proceso. Anteriormente, Pérez y Vázquez (2006) indicaron que en el cultivar 'Tommy Atkins', desarrollado en un clima tropical, su iniciación floral ocurrió con temperaturas diurnas entre 18-20 ㄷ. Por otro lado, hay evidencias que en mango 'Keitt' y 'Tommy Atkins' el PBZ fue capaz de inducir floración con solo dos semanas de temperaturas bajas $\left(20 / 15^{\circ} \mathrm{C}\right.$; día/ noche) (Yeshitela et al., 2004). 
Cuadro 2. Condiciones ambientales durante los meses de octubre a febrero en dos ciclos de floración de mango 'Ataulfo'.

\begin{tabular}{|c|c|c|c|c|c|c|}
\hline \multirow{2}{*}{ Mes } & \multicolumn{3}{|c|}{ Primer ciclo (2013 - 2014) } & \multicolumn{3}{|c|}{ Segundo ciclo (2014 - 2015) } \\
\hline & T máx. $^{+}$ & T mín. ${ }^{++}$ & $\mathrm{PP}^{a}$ & T máx. & T mín. & $\mathrm{PP}$ \\
\hline Octubre & 34.3 & 24.0 & 207.2 & 33.0 & 19.8 & 295.0 \\
\hline Noviembre & 31.1 & 23.1 & 10.0 & 27.9 & 15.8 & 135.0 \\
\hline Diciembre & 30.5 & 19.0 & 55.6 & 27.9 & 15.8 & 0.0 \\
\hline Enero & 31.3 & 15.9 & 56.0 & 29.0 & 16.7 & 0.0 \\
\hline Febrero & 32.9 & 15.7 & 0.0 & 30.0 & 16.9 & 0.0 \\
\hline Marzo & 33.0 & 16.0 & 0.0 & 30.0 & 16.4 & 0.0 \\
\hline
\end{tabular}

†: temperatura máxima; ${ }^{\text {†t}: ~ t e m p e r a t u r a ~ m i ́ n i m a ; ~ p r o m e d i o ~ d e l ~ m e s ~}\left({ }^{\circ} \mathrm{C}\right)$. `PP : precipitación. Datos tomados de la red de estaciones agroclimáticas de INIFAP.

\section{Porcentaje de yemas diferenciadas}

En el primer ciclo, el porcentaje se incrementó con la aplicación de los inhibidores de giberelinas, pasando de 15 $\%$ en el testigo a $38 \%$ con $\mathrm{P}-\mathrm{Ca}$, hasta alcanzar un mayor porcentaje $(P<0.05)$ con la aplicación de PBZ (63\%) (Figura 2A). Durante el segundo ciclo, nuevamente los inhibidores de giberelinas incrementaron $(P<0.05)$ el porcentaje de yemas diferenciadas respecto al testigo (Figura 2B).

En ambos ciclos se logró mayor porcentaje de yemas diferenciadas (E4) con la aplicación de los reguladores con respecto al testigo. Resultados que coinciden con los encontrados por Tongumpai et al. (1996) en mango 'Khiew Sawoey', quienes mencionan que $30 \%$ de las yemas apicales habían desarrollado primordios florales a los 91 días después de la aplicación de PBZ ( $\left.6 \mathrm{~g}_{\text {árbol }}{ }^{-1}\right)$, mientras que las yemas del testigo permanecían vegetativas.

En el presente estudio, durante el primer ciclo en todos los tratamientos hubo brotes con yemas que permanecieron vegetativas durante todo el proceso, lo que probablemente ocasionó una gran cantidad de brotes inactivos, aunque en el testigo el porcentaje fue mayor.

En el segundo ciclo (2014-2015) no hubo brotes inactivos en el tratamiento con PBZ, como con el P-Ca y testigo ( $\approx 45$ y $29 \%$, respectivamente), pero sí se encontraron brotes con yemas en el E2 (iniciación), que dieron lugar más tarde a crecimiento vegetativo. De acuerdo con Bangerth (2009), en árboles frutales una gran cantidad de meristemos permanecen vegetativos, lo que les confiere la perenibilidad, mientras que en plantas anuales todos los meristemos son inducidos a florecer al mismo tiempo, con la consecuente terminación de la vida de las plantas. La perenibilidad está regulada por genes epigenéticos, que evitan o impiden la parcial o total inaccesibilidad de los meristemos a reaccionar a ciertas condiciones endógenas de inducción floral.

\section{Porcentaje de floración}

Al igual que el porcentaje de yemas diferenciadas, los reguladores PBZ y P-Ca aumentaron el porcentaje de floración al pasar de 15 a $30 \%$ (ciclo 1 y ciclo 2, respectivamente) en el testigo, hasta 38 y $45 \%$ (primer y segundo ciclo, respectivamente) con P-Ca y 63 y $70 \%$ con la aplicación de PBZ (Figura 3). El porcentaje de floración logrado en cada tratamiento y ciclo evaluado coincide con el porcentaje de yemas que alcanzaron en E4.

En el primer ciclo se logró adelantar la floración 45 y 30 días con PBZ y P-Ca, respectivamente, y 46 y 36 días en el segundo (Cuadro 1). Los resultados coinciden con los obtenidos por otros autores, donde el PBZ ha sido clave en adelantar la floración en diversos ambientes y cultivares de mango (Pérez-Barraza et al., 2011; Martínez-Fuentes et al., 2013).

\section{CONCLUSIONES}

Tanto PBZ como P-Ca lograron reducir el tiempo de la diferenciación. El PBZ generó mayor porcentaje de yemas diferenciadas que dieron lugar a una mayor cantidad de inflorescencias en época temprana. Sin el uso de inhibidores de giberelinas el inicio de la diferenciación ocurrió más tarde, la duración del proceso fue mayor y la floración fue errática. La iniciación floral en yemas se estimuló con temperaturas nocturnas de alrededor de $15^{\circ} \mathrm{C}$.

\section{BIBLIOGRAFÍA}

Abdel-Rahim A. O. S., 0. M. Elamin and F. K. Bangerth (2011) Effects of paclobutrazol (PBZ) on floral induction and associated hormonal and metabolic changes of biennially bearing mango (Mangifera indica L.) cultivars during off year. Journal of Agricultural and Biological Science 6:55-67.

Atay A. N. and F. Koyuncu (2017) Impact of repeated yearly applications of prohexadione-calcium on vegetative and reproductive growth of 'Golden delicious'/m.9 apple trees. Journal of Horticultural Research 25:47-54. 

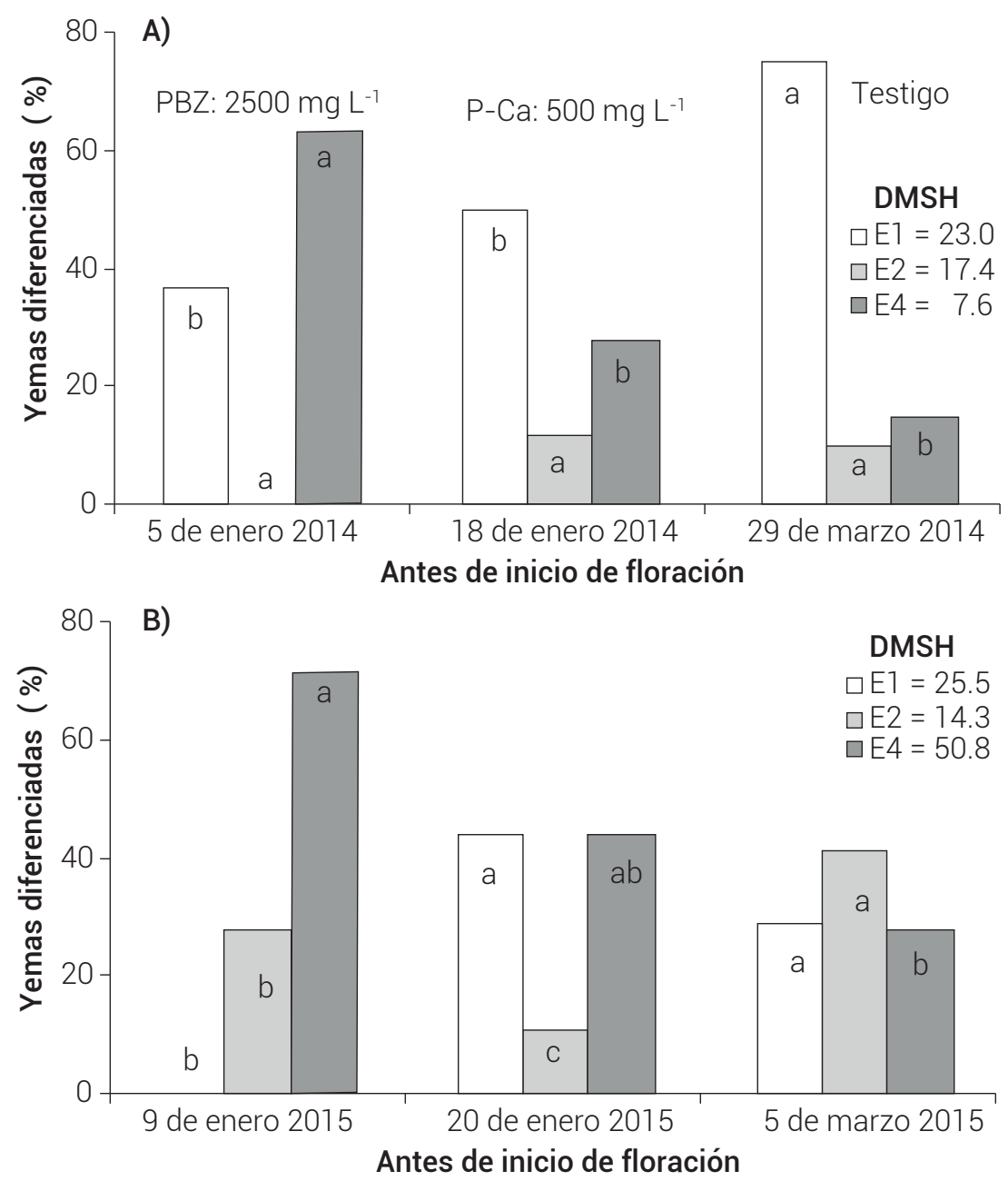

Figura 2. Porcentaje de yemas diferenciadas ocho días antes de inicio a floración de mango 'Ataulfo', durante dos ciclos de floración. A) primer ciclo; B) segundo ciclo. La fecha en ambos ciclos corresponde al momento en que se presentó E4. E1) Yema vegetativa. E2) Iniciación floral. E4) Yema diferenciada. DMSH = Diferencia mínima significativa honesta.

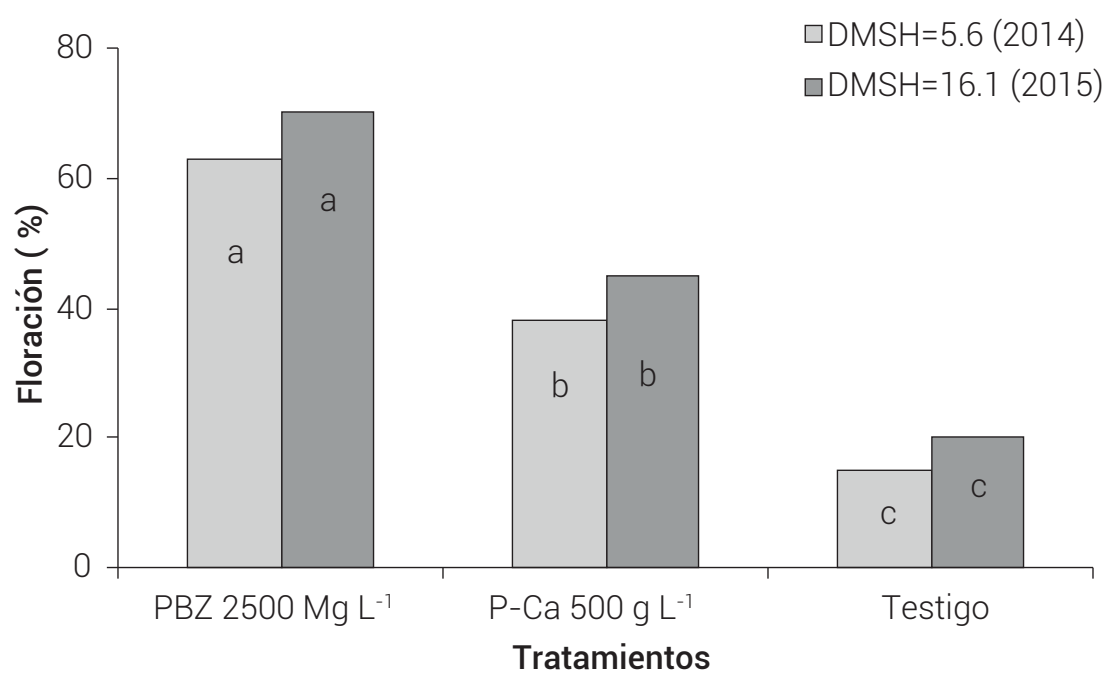

Figura 3. Porcentaje de floración en árboles de mango 'Ataulfo' tratados con inhibidores de la síntesis de GAs, durante los ciclos de floración 2013-2014 y 2014-2015. DMSH: Diferencia mínima significativa honesta. 
Bangerth K. F. (2009) Floral induction in mature, perennial angiosperm fruit trees: Similarities and discrepancies with annual/biennial plants and the involvement of plant hormones. Scientia Horticulturae 122:153-163.

Do Carmo-Mouco M. A., E. O. Ono et E. J. D. Rodriguez (2011) Controle do crescimento vegetativo e floração de mangueiras cv. Kent com reguladores de crescimento vegetal. Revista Brasileira de Fruticultura Jaboticabal 33:1043-1047.

Martínez-Fuentes A., C. Mesejo, N. Muñoz-Fambuena, C. M. C. Reig, D. J. González-Mas, E. Iglesias and M. A. Primo-Millo (2013) Fruit load restricts the flowering promotion effect of paclobutrazol in alternate bearing Citrus spp. Scientia Horticulturae 151:122-127.

Palanichamy V, N. N. S. Reddy, E. Babu, A. Selvaraj and B. Mitra (2012) Determination of time period of fruit-bud-differentiation and the associated histological and biochemical changes in mango hybrids. Research Journal of Pharmaceutical, Biological and Chemical Sciences 3:271-290.

Pérez B. M. H y V. Vázquez V. (2006) Defoliación de brotes apicales y su efecto en la diferenciación floral del mango Tommy Atkins. Revista Fitotecnia Mexicana 29:197-202.

Pérez B. M. H., V. Vázquez V. and J. A. Osuna G. (2009) Floral bud development of 'Tommy Atkins' mango under tropical condition in Nayarit, Mexico. Acta Horticulturae 820:197-204.

Pérez-Barraza M. H., J. A. Osuna-García, R. Sánchez-Lucio y V. VázquezValdivia (2011) El paclobutrazol como promotor de la floración en mango 'Manila', aun sin condiciones ambientales inductivas. Revista Chapingo Serie Horticultura 17:47-52.
Pérez B. M. H., T. Osuna E., E. Avitia G., M. A. Gutiérrez E., M. J. Santiago C. H. Ramírez and R. Cano M (2016) Prohexadiona de calcio reduce crecimiento vegetativo e incrementa brotación floral en mango 'Ataulfo'. Revista Mexicana de Ciencias Agrícolas 7:263-276.

Pérez-Luna A. H., M. A. Gutiérrez-Espinosa, H. A. Zavaleta-Mancera, A. Robledo-Paz y G. Mora-Aguilera (2015) Respuesta histológica a inductores de procesos morfogénicos en Citrus latifolia Tan. Interciencia 40:243-349.

Rademacher W. (2015) Plant growth regulators: Uses in plant production. Journal Plant Growth Regulators 23:845-872.

SAS (2013) SAS Version 9.4. Statistical Analysis System Institute. SAS Institute Inc., Cary, NC, USA.

Sandip M., A. N. Makwana, A. V. Barad and B. D. Nawade (2015) Physiology of Flowering- The Case of Mango. International Journal of Applied Research 1:1008-1012.

Tongumpai P., S. S. Charnwichit and R. O. Subhadrabandhu (1996) Anatomical study of terminal bud development of mango treated with paclobutrazol. Acta Horticulturae 455:175-179.

Upreti K. K., Y. T. N. Reddyb, S. R. Shivu-Prasadb, G. V. Bindua, H. L. Jayarama and S. Rajan (2013) Hormonal changes in response to paclobutrazol induced early flowering in mango cv. Totapuri. Scientia Horticulturae 150:414-418

Yeshitela T., P. J. Robbertse and P. J. C. Stassen (2004) Effects of various inductive periods and chemicals on flowering and vegetative growth of 'Tommy Atkins' and 'Keitt' mango (Mangifera indica) cultivars. New Zealand Journal of Crop and Horticultural Science 32:209-215 
